\title{
TECIDO ÓSSEO ALOGÉNICO NA RECONSTRUÇÃO DOS MAXILARES - UMA ALTERNATIVA VIÁVEL
}

\author{
Allogenic Bone Tissue in Maxillary Reconstruction - A feasible Alternative \\ Edevaldo Tadeu Camarini', Pablo Cornélius Comelli Leite ${ }^{2}$, Karla Bachega ${ }^{3}$, Eduardo Acceturi ${ }^{3}$
}

\begin{abstract}
RESUMO
Objetivo: Os autores propõem demonstrar a efetividade da enxertia óssea alógena na reconstrução do processo alveolar maxilar, com a finalidade de instalação de implantes dentários. Métodos: Utilizou-se a análise clínica e radiográfica pré- e pós-enxertia em seio maxilar (sinus lifting) e após a instalação dos implantes em um caso com evolução de oito anos. Resultados: O exame radiográfico evidenciou uma adequada neoformação óssea, onde puderam ser inseridos implantes dentários que permanecem oito anos, com adequada função clínica. Conclusão: Os aloenxertos ósseos, em função de suas vantagens, podem ser considerados uma alternativa viável à reconstrução de processos alveolares dos maxilares com finalidade implantodôntica.
\end{abstract}

Descritores: Implantes Dentários, Reconstrução, Processo Alveolar, Tecido Ósseo, Transplante e Prognóstico.

\section{Instituição:}

1 Departamento de Odontologia da Universidade Estadual de Maringá - Paraná

2 CESB - Clínica Especializada em Saúde Bucal - Rio do Sul - Santa Catarina

2 UNIOSS - Banco de Ossos de Marília - Marília - São Paulo

\section{Correspondência:}

Edevaldo Tadeu Camarini

Universidade Estadual de Maringá

Av. Mandacarú, 1550

CEP 87080-000 - Maringá - PR

Tel./Fax: 5544 3224-0119

E-mail: edevaldocamarini@wnet.com.brou pablobuco@terra.com.br

Recebido em: 13.02.2007

Aceito em: 26.03 .2007

\section{INTRODUÇÃO}

A descoberta da osseointegração, contato funcional osso/ implante revolucionou a odontologia, permitindo a recomposição de elementos dentários perdidos pela instalação intra-óssea de pinos metálicos constituídos de titânio ${ }^{1}$. Os processos alveolares dos maxilares sofrem um processo de atrofia óssea após a perda dentária, sendo o mesmo variável de paciente para paciente e entre regiões específicas dos maxilares. Em função do grau de atrofia, haverá uma determinada perda óssea que pode comprometer ou impedir a instalação dos implantes. ${ }^{2}$

Na reconstrução desse processo alveolar, os enxertos autógenos foram os primeiros a ser empregados. Aos enxertos autógenos são atribuídas algumas desvantagens como: necessidade de área doadora com sítio cirúrgico adicional e possíveis complicações cirúrgicas, maior tempo cirúrgico e quantidades limitadas de estrutura óssea em função da área doadora. Tais desvantagens podem ser eliminadas quando se opta pela utilização de tecido ósseo alogênico.

Concomitantemente, as técnicas de reconstrução do processo alveolar dos maxilares foram evoluindo. Em se tratando de reconstrução dos processos alveolares dos maxilares, as técnicas de enxertia óssea empregadas são ditadas pelo tipo de defeito a ser reconstruído e, em função deste, pela forma como o material é empregado. Podemos utilizar o tecido ósseo na forma de blocos ou particulado. Em blocos, temos onlays para ganho em espessura ou altura, e na forma particulada, inlays para preenchimento de defeitos ósseos irregulares ou cavidades como os seios maxilares ou fossas nasais. Em relação à região posterior da maxila em função do processo de pneumatização do seio maxilar, o mesmo acaba ocupando o espaço antes ocupado pela estrutura óssea peridentária. Nesses casos, a técnica de eleição é a elevação do seio maxilar através da criação de uma janela óssea na 


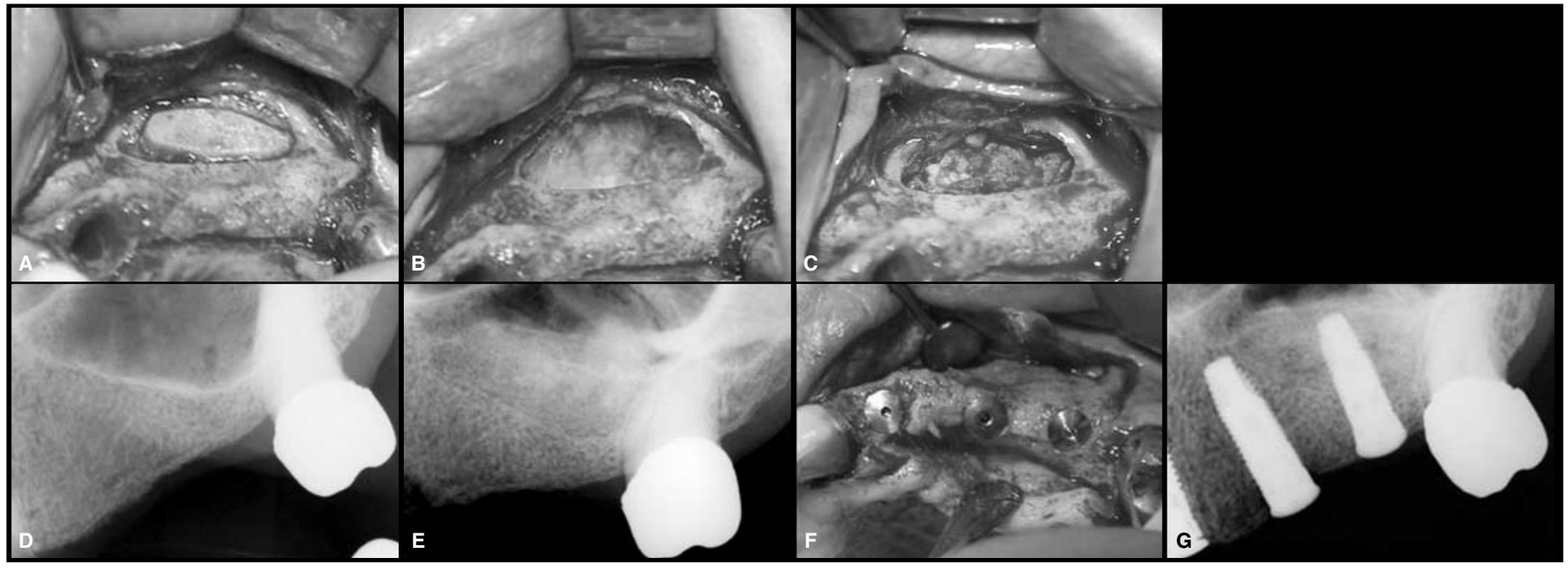

Figura 1: A, B e C - Procedimento cirúrgico demonstrando o preenchimento do seio maxilar. D e E - Avaliação Radiográfica Pré e Pós-enxertia respectivamente, demonstrando o preenchimento sinusal obtido. F - Visão Clínica após seis meses demonstrando os implantes instalados. G - Visão radiográfica dos implantes no interior do enxerto ósseo.

parede anterior do seio e elevação da membrana sinusal, inferiormente à qual será inserido o enxerto ósseo. ${ }^{3}$

Os autores propõem comprovar a efetividade da enxertia óssea alógena na reconstrução dos processos alveolares maxilares através da apresentação de um caso clínico e a discussão da sua efetividade, baseando-se nas características biológicas dos aloenxertos descritos na literatura.

\section{RELATO DO CASO}

Paciente E.T.G., 58 anos, leucoderma, gênero masculino compareceu à clínica de odontologia da UEM (Universidade Estadual de Maringá) com queixa de dificuldade mastigatória por ausência de elementos dentários na região posterior esquerda de sua maxila, desejando submeter-se a tratamento com implantes dentários.

Após o exame clínico e radiográfico, constatou-se a necessidade de enxertia óssea em seio maxilar esquerdo (elevação de seio maxilar), uma vez que os elementos dentários foram perdidos há algum tempo e o seio maxilar já havia passado por um extenso processo de pneumatização. Foi proposta ao paciente a utilização de aloenxerto ósseo, em função da não necessidade da área doadora, procedimento aceito pelo paciente.

O procedimento foi realizado sob anestesia local (mepivacaína $2 \%$ com adrenalina 1:100.000), e após a realização de um retalho trapezoidal, descolamento mucoperiosteal de espessura total, foi realizada ostectomia na parede anterior do seio (antrostomia), criando-se assim um flap ósseo (Figura 1A) que, com a elevação da membrana sinusal, foi projetado juntamente com a membrana para o interior do seio maxilar. Após a completa elevação da membrana sinusal (criação de um espaço), procedeu-se a enxertia óssea alógena particulada, preenchendo o seio maxilar de aproximadamente $12 \mathrm{~mm}$ de altura em toda extensão. Procedeu-se uma vigora compactação do enxerto, visando evitar espaços vazios. A comparação do exame radiográfico periapical (técnica radiográfica) pré-operatório (Figura 1D) com o pós-operatório imediato revela adequado preenchimento ósseo (Figura 1E). Após um período de seis meses (cicatrização do enxerto), foram inseridos os implantes dentários. (Figura $1 \mathrm{~F}$ ).
O exame radiográfico realizado após 8 anos (Figura 1G) mostra a preservação da estrutura óssea perimplantar (enxertia) sem sinais de reabsorção. Clinicamente, os implantes apresentavam-se estáveis, sem sinais de alterações patológicas.

\section{DISCUSSÃO}

Alguns princípios biológicos do processo de incorporação dos aloenxertos devem ser discutidos, numa tentativa de justificar a utilização e os resultados obtidos. O caso demonstrado com a técnica de enxertia óssea sinusal (sinus lifting), visando à instalação de implantes segundo Agahaloo et al (2007) ${ }^{4}$ é a de maior previsibilidade. Assim, as características inerentes à técnica cirúrgica que poderiam contribuir para a falha do aloenxerto ósseo deixam de ser consideradas, apesar de essa técnica apresentar pequenos índices de insucesso.

Enxertos utilizados em substituição ao autógeno deveriam apresentar propriedades osteoregenerativas similares (osteoindução, osteocondução e osteogênese). As propriedades biológicas e vantagens dos aloenxertos são conhecidas, devendo ser consideradas na justificativa de sua utilização e na escolha da forma (bloco ósseo córtico/medular ou particulado) como os aloenxertos devem ser utilizados. Os aloenxertos apresentam propriedades osteocondutivas, atribuídas à estrutura colágena mineralizada, formando um arcabouço que permite a deposição óssea e osteoindutivas pela presença de BMPS (proteínas ósseas morfogenéticas), as quais são liberadas pela atividade osteoclástica, bioestímulo à incorporação do enxerto. ${ }^{5,6,7}$

Com o desenvolvimento da engenharia tecidual, princípios fundamentais para a regeneração de determinados tecidos foram estabelecidos. Dentre eles, a utilização de matriz extracelular similar ao tecido a ser regenerado, uma vez que sua estrutura e composição molecular exercem propriedades químicas e mecânicas requeridas pelas células parenquimais e demandas fisiológicas dos tecidos. ${ }^{8}$ Certas moléculas que compõem a matriz atuam como reguladores insolúveis da função celular, que, no caso do tecido ósseo são as BMP. 
Estas são secretadas por osteoblastos, quando da deposição óssea. ${ }^{9}$ Essas características estão presentes nos aloenxertos.

As BMP (Proteínas Ósseas Morfogenéticas) presentes na matriz são glicoproteínas categorizadas em 15, sendo as de número 2, 4 e 7 de influência no processo osteoindutivo, uma vez que atuam na diferenciação de células mesenquimais pluripotentes. Observou-se através de análise imunohistoquímica que os melhores resultados clínicos (formação óssea), estavam associados ao número de BMP-7 e de BMP-2. O potencial osteoindutivo é variável de banco para banco, e dentro de um mesmo banco, de doador para doador. ${ }^{10}$

Apesar de mais lento e sem a fase osteogênica, o processo de incorporação do enxerto alógeno é similar ao de um enxerto autógeno, cujo processo é bem descrito por Marx. ${ }^{11} \mathrm{O}$ enxerto é colocado em um espaço morto, preenchido com coágulo sanguíneo. $\mathrm{O}$ espaço morto é hipóxico $\left(\mathrm{PO}_{2}\right.$ de 5 a $\left.10 \mathrm{mmHg}\right)$ e acidótico ( $\mathrm{pH} 4$ a 6), contendo plaquetas, leucócitos, células vermelhas e fibrina em uma estrutura complexa. Externamente ao fechamento periosteal, o tecido é normóxico $\left(\mathrm{PO}_{2}\right.$ de 45 a $\left.55 \mathrm{mmHg}\right)$ e apresenta $\mathrm{pH}$ fisiológico ( $\mathrm{pH}$ de 7.42), contém uma população de células estruturais, células fundamentais no processo de cicatrização (embora em pequeno número) e capilares seccionados com coágulo e células endoteliais expostas. ${ }^{11}$

A liberação de fatores de crescimento (PDGF, TGF- $\beta$ e IGF), a partir da degranulação de plaquetas exerce funções primordiais no processo regenerativo. Destacam-se a atividade angiogênica dos brotos capilares no interior do enxerto pela indução da mitose em células endoteliais, diferenciação e proliferação de fibroblastos e pré-osteoblastos em osteoblastos funcionais, secreção de matriz óssea pelos osteoblastos e matriz colágena pelos fibroblastos, dando suporte ao crescimento capilar. Em enxertos autógenos, por volta do terceiro dia, são vistos capilares penetrando no enxerto, e a penetração completa é visualizada do $14^{\circ}$ ao $17^{\circ}$ dia. ${ }^{11}$

Nos enxertos autógenos, a formação de osso fase I, origina-se de osteoblastos endosteais que delimitam as superfícies ósseas trabeculares. Este osso fase I é imaturo e desorganizado com ausência de sistemas de havers e pouca integridade estrutural. Desenvolve-se após quatro semanas do enxerto. O término da revascularização do enxerto elimina a pequena tensão de oxigênio necessária para manter a atividade dos macrófagos. Os mesmos deixam a área, pois não são mais necessários para a manutenção do enxerto. O osso fase I irá, então, obrigatoriamente, ser submetido a um processo de reabsorção/ aposição, que levará à formação de um osso maduro com arquitetura lamelar e sistemas de havers, denominado osso fase II. Este, com um periósteo e endósteo já desenvolvido, é um osso auto-sustentável com total integridade estrutural. ${ }^{11}$

A maturação do osso regenerado envolve o IGF e proteínas ósseas morfogenéticas. Estas são proteínas ácidas insolúveis, liberadas pela reabsorção osteoclástica no processo de remodelamento ósseo normal, o qual ocorre na proporção de $0,7 \%$ por dia no osso normal, podendo ocorrer tão rapidamente como $5 \%$ a $8 \%$ por dia num enxerto no processo de maturação. A liberação de BMP e IGF liga a reabsorção óssea à neoformação, atuando em células pluripotentes adjacentes e pré-osteoblastos, induzindo sua proliferação e diferenciação em osteoblastos funcionais, os quais secretam ativamente a matriz óssea. Deste modo, o ciclo do enxerto progride de um transplante celular, o qual é colocado em um complexo ambiente biomecânico a um osso maduro e funcional, o qual é auto-sustentável através de um ciclo normal de reabsorção/ remodelamento. ${ }^{11}$

Os princípios fisiológicos da integração de qualquer transplante ósseo consideraram a reabsorção osteoclástica como bioestímulo à neoformação óssea. $\mathrm{O}$ remodelamento do enxerto repercute na sua proporção de mineralização, influenciando o prognóstico dos implantes instalados no enxerto. ${ }^{11} \mathrm{O}$ processo de incorporação do enxerto com formação de osso primário imaturo inicialmente e sua maturação em osso secundário lamelar estão relacionados à vascularização do enxerto, que depende do próprio enxerto e do leito receptor. Estruturalmente, os enxertos são compostos de uma porção cortical e outra medular. A medular é muito mais facilmente vascularizada e incorporada e mais facilmente reabsorvida.

A influência no processamento dos aloenxertos também deve ser considerada, uma vez que influenciará em seu potencial osteoregenerativo. O método de processamento dos aloenxertos deve garantir a esterilização, preservação das características biológicas e redução da antigenicidade. ${ }^{12} \mathrm{O}$ osso utilizado por nós passou por processo de tratamento ácido com $\mathrm{HCl}$ estéril associado a uma solução de Ca à 5\%, bombeamento em água por 12 horas, liofilização, e armazenado à $-80^{\circ} \mathrm{C}$, o que garante sua viabilidade por cinco anos. Tal processamento garante a esterilização do mesmo e a preservação das propriedades biológicas osteoindutivas e osteocondutivas. No entanto, a cuidadosa seleção do doador é fundamental na prevenção da transmissão de doenças infecto-contagiosas.

Os aloenxertos ósseos apresentam-se como uma alternativa viável à reconstrução de maxilares com a finalidade de instalação de implantes dentários. Por um lado, o enxerto com características estruturais (cortical/medular) e biológicas (quantidade e tipo de BMP presentes) e de outro o próprio receptor com sua inerente atividade osteoclástica são as variáveis que influenciarão na variabilidade dos resultados clínicos obtidos.

\section{CONCLUSÃO}

Os aloenxertos ósseos apresentam-se como alternativas viáveis quando da reconstrução dos maxilares com finalidade implantodôntica. As vantagens de eliminação da área doadora associadas às propriedades biológicas osteoregenerativas descritas na literatura fornecem embasamento científico a sua utilização.

\section{ABSTRACT}

Purpose: The authors propose to demonstrate the allogenic bone grafting related to the reconstruction of the maxillary alveolar process for dental implant installation. Methods: clinical and pre and post grafting radiographic analysis were used on the maxillary sinus (sinus lifting) and after implant installation in an eight years case evolution. Results: The radiographic examination showed an appropriate bone 
neo formation able to receive dental implants which remained properly functional for eight years. Conclusion: due to their advantages, allograft bones can be considered a good alternative related to alveolar processes reconstruction of the maxillary for dental implant.

Keywords: Dental Implants, Reconstruction, Alveolar Process, Bone Tissue, Transplant and Prognosis.

\section{REFERÊNCIAS}

1 Branemark P-I, Zarb GA, Albrektsson T. Tissue integrated Prosthesis: Osseointegration in Clinical Dentistry Chicago, Quintessence, pp 11-17,2111-2233, 1985.

2 Watzek G, Webwr R, Bernhart T, Ulm C, Haas R. Treatment of patients with extreme maxillary atrophy using sinus floor augumentation and implants:preliminary results. Int J Oral Maxillofac Surg, 1998;27(6):51-57.

3 Gark AK. Augmentation grafting of the maxillary sinus for placement of dental implants: anatomy,physiology and procedures. Implant Dent 1990;8(1):36-46.

4 Aghallo TL, Moy PK. Which Hard Tissue Augmentation Techniques Are the Most Successful in Furnishing Bony Support for Implant Placement? Int J Oral Maxillofac Implants, 2007;22 (SUPPL):49-70

5 Marx RE, Kline SN, Johnson RP, Malinin TI, Matthews JG, Gambill V. The use of freeze-dried allogeneic bone in oral and maxillofacial surgery. J Oral Surg. 1981;39(4):264-274.
6 Wong ME. Symposium on adjunctive therapy in bone healing: Allogenic Bone and Bone Healing, J Oral Maxillofac Surg. 2005.

7 Zhang M. Effect of the demineralized process on the osteoinductivity of demineralized bone matrix. J Periodontal. 1997;68:1085-92.

8 Lynch SE, Genco RJ, Marx RE. Basic Principles of Tissue Engineering. Tissue Engineering: Aplications in Maxillofacial Surgery and Periodontics. 1999; Cap. 1, p. 3-16.

9 Lynch SE, Genco RJ, Marx RE. Basic Principles of Tissue Engineering. Tissue Engineering: Aplications in Maxillofacial Surgery and Periodontics. 1999; Cap. 1, p. 3-16.

10 Han B, Tang B, Nimni ME. Quantitative and sensitive in vitro assay for osteoinductive activity of demineralized bone matrix Journal of Orthopaedic Research. 2003;21:648-54.

11 Garg AK, Marx RE. Bone Structure, Metabolism, and Physiology: its impact on Dental Implantology. Implant Dentistry. 1998;7(4):267-76.

12 Vastela L. et al. P. Effect of different sterilization processing methods on the mechanical properties of human cancellous bone allografts. Biomaterials 2004; 25:2105-10. 